\title{
La línea 12 en la mira de la sociología de las élites delincuentes
}

\author{
Mexico City Subway Line 12 through the Scope of the Sociology of Criminal Elites
}

\author{
Vicente Ugalde*
}

Resumen: El cierre parcial de la línea 12 del Metro durante 2014 puso al descubierto una serie de decisiones técnicas, políticas y financieras tomadas de manera errática y, en ocasiones, inaceptables por la ética pública. Este artículo analiza las reacciones por parte de las instancias de control administrativo, de procuración de justicia, de representación política y de la sociedad a las desviaciones a las normas jurídicas y a las convenciones éticas y profesionales, enfocándose en los comportamientos asociados con la corrupción y los delitos de cuello blanco. En primera instancia se delinean las preocupaciones centrales de la sociología de las élites delincuentes, para posteriormente resaltar los elementos más importantes del caso de estudio. Finalmente, se concluye poniendo en evidencia la productividad intelectual del affaire de la línea 12 del Metro desde la perspectiva que propone la sociología de las élites delincuentes.

Palabras clave: sociología de élites criminales, análisis de políticas públicas, delito de cuello blanco, corrupción, línea 12 del metro.

Abastract: The partial closure of the Mexico City Subway line 12 during 2014 exposed a series of technical, political and financial decisions which were erratic, did not follow existing regulations and were sometimes defiant of public ethics. This paper analyses the administrative, political and social reactions to the deviations form legal norms as well as from ethical and professional conventions focusing on behaviors frequently associated with corruption and white-collar crime. After outlining the core concerns of the sociology of criminal elites, the major elements of the case study will be highlighted. Finally, the paper concludes by drawing attention to the intellectual productivity of the Subway Line 12 affaire according to the sociology of criminal elites.

Keywords: sociology of criminal elites, public policy analysis, white-collar crime, corruption, Mexico City subway line 12 .

*Vicente Ugalde es profesor-investigador del Centro de Estudios Demográficos, Urbanos y Ambientales de El Colegio de México. Carretera Picacho Ajusco 20, Ampliación Fuentes del Pedregal, Tlalpan 14110, Ciudad de México, México. Tel: 5554493000 , ext. 3101. Correo-e: vugalde@colmex.mx. ORCID: 0000-0002-0470-2929. $\mathrm{El}$ autor agradece las observaciones y recomendaciones de los revisores anónimos.

Artículo recibido el 7 de marzo de 2017 y aceptado para su publicación el 18 de julio de 2017. 


\section{INTRODUCCIÓN}

- 1 cierre parcial de la línea 12 (L12) del Metro ha puesto al descubierto las numerosas facetas que supone una obra pública de esa envergadura: la sucesión de decisiones no únicamente conciernen aspectos técnicos, sino que en muchos casos se trata de decisiones en las que intervienen consideraciones políticas y sobre todo financieras. La decisión de detener su funcionamiento puso en evidencia, sobre todo, que se tomaron decisiones erráticas y que además intervinieron conductas que no se apegaron a lo previsto por las reglas jurídicas que organizan la toma de decisiones en ese tipo de asuntos, así como conductas que parecen no haberse ajustado a lo que la ética pública tiene por aceptable. Estas primeras evidencias desencadenaron una serie de reacciones por parte de las instancias de control administrativo, de procuración de justicia, de representación política, pero también reacciones de la sociedad. Es justamente sobre las reacciones a esas desviaciones a lo previsto por normas jurídicas pero también a convenciones éticas y profesionales, sobre lo que se plantea una reflexión en este artículo. Si bien la ciencia política y la administración pública ofrecen diferentes enfoques teóricos para analizar los principales problemas e implicaciones político-administrativas y las repercusiones institucionales y organizacionales de ese caso, el objetivo de este artículo es ampliar el perímetro de los enfoques movilizados, para pensar este evento también desde una perspectiva que se interesa en los comportamientos que generalmente se asocian con la corrupción, los delito de cuello blanco y, en general, con lo que es del interés de la sociología de las élites delincuentes, enfoque planteado por el trabajo de Pierre Lascoumes y Carla Nagels (2014), que hemos tomado como referente principal para este ejercicio.

La elección de este enfoque no significa que el estudio de un asunto como el que nos ocupa carezca de interés para otros. La pertinencia de considerar el caso de la línea 12 del metro para el análisis de políticas públicas es evidente, no sólo porque permite analizar la capacidad de los medios de comunicación para influir y modelar la agenda pública (Parsons, 2005), sino también porque, en tanto constituye un caso portador de cierta intensidad dramática (inmovilizar un medio de transporte de alto costo por fallas técnicas, además de que se deja sin servicio a 400 mil personas), hace que éste se convierta en el evento que plantea de forma exacerbada algo y hace posible que rápidamente se le asigne la categoría de "problema público", es decir, de problema que requiere una intervención inmediata (Hassenteufel, 2008). Algunos estudios sobre la definición de problemas públicos (Kindong, 1984) y, en general, sobre la acción pública (Lascoumes y Le Galès, 2014) señalan que eventos concretos pueden desempeñar un papel en las 
condiciones que hacen posible que un tema se inscriba en la agenda y dé lugar a una respuesta pública.

Para articular la reflexión que plantea este texto, en primer término se esbozan las preocupaciones o interrogaciones centrales de este enfoque. Este acercamiento a la perspectiva de la sociología de las élites delincuentes se basa en la revisión del trabajo recientemente publicado sobre este tema. En un segundo momento, luego de presentar los aspectos del caso de la L12 del Metro de la Ciudad de México, el artículo esboza, desde las preocupaciones de la sociología de las élites delincuentes, algunas interrogaciones para orientar el estudio de este caso. El propósito de proceder de esta manera es poner en evidencia lo que podría ser la productividad intelectual del caso de la L12 desde la perspectiva que propone la sociología de las élites delincuentes.

\section{LOS ENIGMAS SOCIOLÓGICOS DE LA DELINCUENCIA DE ÉLITES}

El trabajo reciente de Lascoumes y Nagels sobre la sociología de las élites delincuentes se interesa en las transgresiones que se llevan a cabo en el marco de una función profesional o electiva de actores que tienen una responsabilidad de dirección. El trabajo constituye una tentativa, desde nuestro punto de vista exitosa, para llevar al contexto francés y a la época contemporánea, los estudios de criminología de las élites que se derivan del trabajo de Edwin Sutherland, ${ }^{1}$ en el que propuso el concepto de "delito de cuello blanco" y la teoría criminológica de la "asociación diferencial". Lascoumes y Nagels distinguen, por un lado, la delincuencia económica y financiera y, por el otro, la delincuencia de las élites políticas. En este trabajo retomamos las interrogaciones y preocupaciones que orientan la investigación sociológica de ambos campos y que estos autores agrupan en la noción de élites delincuentes. Consideramos los dos campos no sólo por economía de espacio sino debido a que, como lo dejan ver algunos autores (como Mills, 1956 y Moroff, 2004, citados por Lascoumes y Nagels, 2014), las interacciones y la cercanía entre ambos campos tiene como expresión y consecuencia el que tanto la delincuencia económica y financiera como la de las élites políticas compartan explicaciones en cuanto a sus causas y funcionamiento. ${ }^{2}$ en 1969.

${ }^{1}$ En especial su obra White Collar Crime de 1949. Existe una traducción al español publicada en Venezuela

${ }^{2}$ Este enfoque es sin duda también deudor del trabajo de Morris sobre los "Upperworld crimes" (Geis, 2007). Una clara revisión de estos estudios sociológicos también susceptibles de ser considerados como una variante de la criminología puede verse en Newman (1958). 
El trabajo de Lascoumes y Nagels (2014) advierte que lo que ha llamado la atención de los especialistas a propósito de las conductas delincuenciales o social y moralmente reprobables de ciertas élites públicas y privadas es que, a pesar de expresiones reiteradas y sonadas de indignación, tanto en la prensa y en los circuitos convencionales de discusión pública, esas conductas, esos affaires, raramente generan sanciones severas. Es decir, la severidad de las sanciones judiciales raramente está a la altura del tamaño de la reprobación social inmediata que generan esos escándalos. ${ }^{3}$ Estos autores observan que a una denuncia muy sonada, muy ruidosa, suele corresponder una reacción social débil, lo que para ellos constituiría una situación sociológicamente enigmática.

La discusión sobre este tipo de enigmas es escasa en México. Eso no significa que la producción académica sobre categorías y discusiones que se aproximan al enfoque de las élites delincuentes sea inexistente. Además de la producción científica en criminología desde la perspectiva del tipo de falta (Mugellini, 2014) ${ }^{4} \mathrm{o}$ del tipo de actor (Vilalta y Fondevila, 2013), ${ }^{5}$ hay un número considerable de trabajos sociológicos sobre delincuencia organizada y desde luego sobre los denominados delitos de cuello blanco (Fernández y Arellano, 2010; Roque, 2011; Plascencia, 1995). Lo que sorprende es que, a pesar de que se trata de una amplia literatura, en el análisis de la delincuencia de cuello blanco no suele aparecer el tema de que estas actividades ponen en riesgo el orden social, algo que sí aparece cuando se habla del crimen organizado, o los delitos del orden común contra la seguridad, la vida (homicidio) y la salud personal (lesiones) o contra la libertad de las personas (secuestro). Aparece aquí la cuestión sobre si en verdad existe esa inocuidad social cuando se trata de delitos blancos. Y es que cuando se habla de élites no se trata únicamente de delitos fiscales, sino también, ${ }^{6}$ como es el caso

\footnotetext{
${ }^{3}$ La disociación entre la reprobación social generada por acciones de responables políticos y gubernamentales y las consecuencias en términos de sanciones, especial pero no exclusivamente en términos electorales, ha sido explorada por numerosos especialistas tanto en contextos estadounidenses como europeos. Véase la síntesis que proponen Bezes y Lascoumes (2005).

${ }^{4}$ Sobre este punto y en referencia a la nota anterior, debe señalarse aquí el valioso trabajo publicado por el INEGi y coordinado por Giulia Mugellini (2014). Se trata de un trabajo de medición y análisis sobre la delincuencia en el que el sector empresarial es la víctima (generalmente de sus propios empleados); ahí se analiza por ejemplo, cuáles son los delitos que se cometen contra este sector, quiénes son sus autores materiales, cuál es el efecto y el costo de estos delitos y, entre otras cosas, por qué este tipo de conductas no es un hecho ampliamente reconocido. El trabajo incluye numerosos datos y estadísticas sobre la comisión de este tipo de delitos.

${ }^{5}$ Esta obra es resultado de un amplio trabajo empírico sobre los perfiles delictivos de la población carcelaria, a partir de encuestas aplicadas en centros de reclusión en el Distrito Federal y el Estado de México. Se trata de la recolección y análisis de información de esa población (aspectos demográficos, de su contexto familiar, su historia criminológica, su educación, trayectoria ocupacional, la naturaleza y monto de los delitos, etc.); así como información sobre las víctimas.

${ }^{6}$ Los delitos fiscales y sus sanciones se encuentran definidos en diferentes leyes aunque la principal es el Código
} 
que nos interesa, de delitos contra el servicio público cometidos por particulares regulados, para este caso previstos en el Código Penal del Distrito Federal.

A propósito de cómo las poblaciones perciben y valoran las conductas relacionadas con los delitos de cuello blanco, son escasos los trabajos empíricos, no sólo en México, sino a nivel internacional. Entre los trabajos que han abierto la discusión sobre este tema debe sin duda ser mencionado el de Del Pont y Nadelsticher (1981) en el que, al comparar a sujetos de delitos de cuello blanco con respecto a los de delitos convencionales, se buscó identificar diferencias en las representaciones del público sobre este tipo de delitos con respecto a delitos convencionales. El estudio se interesó en identificar diferencias en cuanto a la reacción emocional (rechazo total), la reacción instrumental (qué tipo de sanción prefiere el encuestado aplicar a tal o cual conducta), la reacción victimológica (qué tipo de sanción cuando el encuestado es la víctima), así como las diferencias en función de la edad, la profesión, el ingreso o el sexo del encuestado. Se identificó por ejemplo, que hay diferencia en las representaciones de estos dos tipos de delito; que en la medida en que la edad del público, su ingreso o su nivel cultural aumenta, su rechazo a los delitos de cuello blanco es mayor. Igualmente ese trabajo identificó que ciertas profesiones así como el hecho de ser hombre supone una mayor propensión a rechazar ese tipo de delitos.

También es interesante este estudio cuando revela que la población piensa que el castigo más adecuado para los delitos convencionales es la privación de la libertad, mientras que para los delitos de cuello blanco la sanción más citada es una reprensión ante el público y no la prisión (Del Pont y Nadelsticher, 1981: 124).

Sobre las respuestas sociales ante los comportamientos delictivos de las élites, Lascoumes y Nagels (2014) se refieren a dos estudios (Wolfgang et al., 1985 y Tremblay, Leclerc y Bouchard, 2006), el primero de ellos llevado a cabo en Estados Unidos en el marco de la Encuesta Nacional sobre la Gravedad del Crimen (NSCS) y el segundo, realizado por un equipo de investigadores de la Universidad de Montreal. Con metodologías asimilables pero no iguales, estos dos trabajos arrojaron interesantes observaciones a propósito del papel que desempeña la valoración sobre las consecuencias del acto sobre la salud así como algo que podría considerarse un criterio económico, es decir, relacionado con el monto, cuando el daño o afectación son cuantificables. En ese caso, la valorización de la gravedad del acto estaría dada sobre todo por la gravedad del daño provocado. Otro trabajo

Fiscal de la Federación que les dedica un capítulo a éstos y otro a las infracciones fiscales. El Código Fiscal se publicó en el Diario Oficial de la Federación del 31 de diciembre de 1981, su última reforma data del 14 de marzo de 2014. 
citado por Lascoumes y Nagels (Rebovich y Laine, 2000) sugiere que, en Estados Unidos, donde se realizó la investigación, en los últimos años hay una mayor sensibilidad hacia los delitos de cuello blanco. Esta investigación también se aboca, entre otras cosas, a identificar el nivel de gravedad que los encuestados atribuyen a diferentes conductas asociadas a delitos económicos y financieros. Así, 74 por ciento de los encuestados considera como lo más grave que un servidor público acepte un soborno, sólo 12 por ciento considera más grave que sea un ciudadano el que lo ofrezca, y únicamente para 14 por ciento de encuestados, las dos conductas serían consideradas igualmente graves. En efecto, la valoración es más severa cuando se trata de un servidor público que si se trata de un ciudadano. Aunque entre un ciudadano y una empresa, la valoración es más severa tratándose de esta última.

El estudio del comportamiento delictivo de las élites conlleva, por otra parte, dos rasgos que han vuelto complejo su análisis. Por un lado, la dificultad para calificar algunos actos pues, primero, hay que definir con respecto a qué norma se valora la conducta presuntamente transgresora (jurídica o no jurídica y, en cada caso, de qué tipo: moral, profesional, o bien si es jurídica, de qué rama: responsabilidad de servidores públicos, derecho financiero, derecho fiscal, de higiene industrial, ambiental, etc.) y luego hay que determinar si efectivamente se trata de una transgresión. Por otro lado, los especialistas identifican otra dificultad en la incertidumbre asociada con el señalamiento y el seguimiento de esos comportamientos, pues en general son difícilmente perceptibles (por los tecnicismos fiscales y financieros), son percibidos como poco dañinos (frente, por ejemplo, al tráfico de estupefacientes o la privación de la libertad de las personas), y son difíciles de acreditar en procedimientos jurisdiccionales (el recurso a personas morales, el secreto bancario, la secrecía de documentación administrativa o empresarial).

Los análisis que aparecen en la prensa suelen abocarse más a la transgresión de las normas en vigor que a la forma en cómo las élites inciden en la elaboración de esas normas y, por lo tanto, en la definición de las conductas susceptibles de ser sancionadas. Es en los procesos de criminalización de conductas en donde concentran sus esfuerzos. Lascoumes y Nagels nos recuerdan que para algunos especialistas (se refieren a Reiss y a Tonry), la violación directa de las leyes suele ser tan problemática como el lobbying que hacen algunos actores para incidir en la definición de infracciones en el marco institucional (Lascoumes y Nagels, 2014: 49).

Otro rasgo que vuelve complejo el análisis de la delincuencia de las élites y que tampoco sería ajeno a nuestro caso concierne a la diversidad de situaciones que 
pueden aparecer, es decir, que son susceptibles de ser consideradas como objeto de estudio de la sociología de las élites delincuentes. El trabajo de Mugellini (2014) da cuenta de que no todos los delitos contra las empresas del sector privado serían de interés para un enfoque que se centra en los delitos que cometen las élites políticas y empresariales, pero al mismo tiempo revela que muchos de los casos de corrupción no necesariamente se refieren a grandes sumas de dinero sino, con independencia del monto, a actos de soborno en los que (según el cuestionario de la encuesta aplicada), ${ }^{7}$ algún servidor público hubiera solicitado de forma expresa algún regalo, favor o dinero a la unidad económica en cuestión; en los que alguna tercera persona le hubiera solicitado un regalo o dinero a nombre de un servidor público, o bien que algún servidor público hubiera insinuado o propiciado condiciones para que se diera algún regalo o dinero. A lo anterior puede adicionarse la complicación que supone que la percepción de la corrupción sobreestima sus niveles reales, si bien éstos son alarmantes. La Encuesta Nacional de Calidad e Impacto Gubernamental 2013 (ENCIG) ${ }^{8}$ es reveladora de que, a pesar de esa sobreestimación, la incidencia de actos de corrupción es, en efecto, alarmante.

Nuestra decisión de movilizar para este análisis la sociología de las élites delincuentes no omite que al abordar el tema de los comportamientos pueden aparecer problemáticas muy diversas. En nuestro caso, al tratarse de una gran ciudad investida por el rasgo del reciente cambio democrático, rápidamente se impone la consideración sobre la relación entre corrupción y democracias. En efecto, una idea de progreso moral, muy arraigada en el pensamiento contemporáneo, supone una asociación entre gobiernos autoritarios o predemocráticos y corrupción y, en consecuencia, que con el advenimiento de la democracia se abatiría la corrupción. Algunos estudios advierten que, por el contrario, la corrupción persiste en las democracias e incluso es un factor considerado con especial atención en los numerosos estudios sobre el desencanto democrático. ${ }^{9}$ Desde

\footnotetext{
${ }^{7}$ Nos referimos a las preguntas del cuestionario de la Encuesta Nacional de Victimización de Empresas 2012 del INEGI.

${ }^{8}$ Según los resultados de esta encuesta, de la población total que realizó al menos un trámite durante 2013, 47.6 por ciento manifestó creer que en ese trámite se daban actos de corrupción, 32 por ciento señaló conocer a alguien que sufrió algún acto de corrupción en ese mismo trámite y 12.1 por ciento dijo haber sufrido el acto de corrupción en el trámite en cuestión (INEGI, 2014).

${ }^{9}$ Sin ser el factor central, la corrupción se asoma en dos de los más citados estudios sobre la pérdida de confianza en la democracias (Crozier, et al., 1975; Pharr y Putnam, 2000; Lascoumes, 2011). Una revisión sistematica de la producción científica sobre la relación entre las valoraciones sobre la corrupción y la confianza en las democracias occidentales se encuentra en Bezes y Lascoumes (2005).
} 
este punto de vista, la corrupción tiende a instalarse como un comportamiento constante en las prácticas por las que los agentes sociales se relacionan con las reglas de la colectividad, independientemente del régimen político del que se trate. Dos rasgos de las sociedades democráticas parecen insuficientes para contradecir esta idea: la capacidad de los cuerpos de justicia de los Estados democráticos para sancionar la corrupción (en nuestro contexto nacional es elocuente el dato de la Auditoría Superior de la Federación, de acuerdo al cual, de 444 denuncias penales presentadas en los últimos años, sólo siete generaron una consignación) y, por otro lado, la escasa reacción del electorado o de las burocracias de los partidos para castigar ese tipo de comportamientos: los partidos siguen postulando personas involucradas en escándalos, y las ciudadanías siguen votando por ellos (en recientes procesos electorales es posible encontrar ejemplos de postulaciones a cargos de elección popular de personas involucradas en casos o escándalos que ponen en entredicho su probidad pública. Más allá de que las direcciones de los partidos políticos habrían sido objeto de algunos señalamientos y reproches en las tribunas de los medios de comunicación, esas nominaciones no parecen haber tenido efectos notorios en el comportamiento del electorado).

Otra cuestión se refiere a si la discusión sobre este tipo de conductas por parte de las élites se reduce a la transgresión de normas jurídicas establecidas. Si bien en las leyes y reglamentos del marco jurídico que regula a los servidores públicos, así como aquellas que regulan diversas actividades de las élites empresariales, se han multiplicado las definiciones de infracciones y delitos, creemos que es posible preguntarnos si no formarían parte de la construcción de un problema de investigación y de reflexión académica algunas otras prácticas que, sin estar expresamente prohibidas por el derecho vigente, pueden ser consideradas como transgresiones a una cierta ética del servicio público (o del profesional). Si al cabo de un proceso administrativo o penal no se determina la responsabilidad de ningún funcionario público ni de ninguna de las empresas participantes en la construcción de la L12 del metro, ¿̇las decisiones que ahí se tomaron y las acciones que se implementaron no constituirían algún tipo de práctica contra la ética susceptible de constituir un objeto de estudio sobre la probidad moral de las élites?

\section{MÉXICO Y EL AFFAIRE DE LA LÍNEA 12 COMO TERRENO DE REFLEXIÓN}

El caso de la línea 12 del Metro de la Ciudad de México es susceptible de revisarse desde el plano a partir del cual se han formulado algunos de los cuestionamientos clave de la sociología de las élites delincuentes. Por ello, luego de una 
rápida presentación de los elementos generales del affaire de la L12, se procede a plantear algunas interrogaciones y observaciones potencialmente generadoras de temas de interés para un análisis de lo ocurrido en este caso.

\section{El alumbramiento del affaire}

El 12 de marzo de 2014 la prensa nacional, al unísono, anunciaba el cierre temporal de once de estaciones, de Atlalilco a Tláhuac, todas en la parte elevada de la recién inaugurada L12. Según Joel Ortega, entonces director del Sistema de Transporte Colectivo Metro, la decisión obedecía a necesidades de diagnóstico y mantenimiento mayor, debido a que presentaban un riesgo para los usuarios. Unos meses más tarde, la autoridad judicial libraba ordenes de aprehensión contra altos funcionarios del gobierno del Distrito Federal que habían estado involucrados en el proceso de construcción de la L12; en primer término contra Juan Manuel Martínez Juárez, que se había desempeñado como subdirector de costos y concursos del Proyecto Metro, y contra de Abraham Vizcarra Baltazar, que había sido Jefe de la Unidad Departamental de Concursos, ambos por el delito del uso ilegal de atribuciones y facultades en la L12 del Metro; ${ }^{10}$ luego, el titular de la entidad Proyecto Metro, encargada de coordinar la construcción, el ingeniero Enrique Horcasitas, y más tarde la Procuraduría General de Justicia informaba que se había procedido penalmente contra Juan Armando Rodríguez por de delito de concusión. ${ }^{11} \mathrm{Al}$ tiempo que la prensa se apresuraba a dar cuenta de las aprehensiones y de otras acciones en contra de ex funcionarios, el jefe de gobierno del Distrito Federal detenía la ola de especulaciones sobre una investigación y la correspondiente orden de aprehensión en contra del anterior jefe de gobierno Marcelo Ebrard. ${ }^{12}$ La persecución materializada, principalmente a través de

${ }^{10}$ En 2015 estos dos funcionarios habían sido ingresados en el reclusorio Norte de la capital del país y luego condenados a una pena de prisión de un año quince días, pero en marzo de 2017 se dio a conocer que un tribunal federal les había concedido el amparo y protección de la justicia federal, con lo que su sentencia fue anulada. Véase "La PGJ capitalina impugnará, mediante recurso de revisión, amparo concedido a dos implicados en la construcción de la Línea 12 del Metro" comunicado de la Procuraduría General de Justicia de la Ciudad de México del 30 de marzo de 2017. Disponible en: http://www.pgj.cdmx.gob.mx/comunicacion/nota/CS2017-269 [fecha de consulta: 30 de junio de 2017].

${ }^{11}$ En mayo de 2017 el diario Excélsior informaba que otro funcionario había sido puesto en prisión. Se trata del director de Administración de Contratos de Proyecto Metro, acusado de fraude por más de cinco millones de pesos en perjuicio del gobierno de la ciudad y quien había contratado a la firma ILF Ingenieros Consultores, que según el reporte de prensa se hizo pasar como filial de ILF Beratende Ingenieure AG, a la que se le asignaron los trabajos de dictaminación para determinar los motivos, recomendaciones y acciones para minimizar los problemas presentados por el desgaste de rieles. Véase Excélsior, disponible en: http://www.excelsior.com.mx/comunidad/2017/05/14/1163487 [fecha de consulta: 30 de junio de 2017].

${ }^{12}$ Numerosos medios dieron cuenta de lo declarado por el jefe de gobierno Miguel Ángel Mancera a inicios del 
especulaciones formuladas y planteadas en medios de información, había pasado al terreno de las instancias de procuración de justicia sin involucrar ni evocar al jefe de gobierno de la administración responsable de la construcción de la L12. La intensa difusión del cierre de ese medio de transporte, de sus causas, de sus primeros efectos y de las acciones para fincar responsabilidades perfilaban que se trataba de un verdadero affaire ${ }^{13}$ en el que la acción penal difícilmente podría quedar al margen.

Fue en 2008 cuando el gobierno del Distrito Federal anunciaba que la entidad ganadora del proceso de licitación para la construcción de la L12 del Sistema de Transporte Colectivo Metro, Tláhuac-Mixcoac, publicado en enero de ese año, ${ }^{14}$ era la empresa Ingenieros Civiles Asociados, SA de CV, otorgándole el contrato para la construcción de la obra civil y electromecánica a precio alzado y tiempo determinado para su ejecución y quedando pactada en 17583500000 pesos. ${ }^{15}$ Para la adquisición de los trenes, en mayo de 2010, el Sistema de Transporte Colectivo contrató con la empresa CAF que ésta pusiera a disposición de la línea 12 del Metro 30 trenes nuevos de rodadura férrea, contrato que incluía el mantenimiento, el equipamiento, las refacciones y la readecuación de talleres, todo por un poco más de 1500 millones de dólares. ${ }^{16}$ Fue el 30 de octubre de 2012

mes de julio de 2015. Véase a guisa de ejemplo: "MAM: no se investiga a Ebrard por la L12", en El Universal en línea: http://www.eluniversal.com.mx/articulo/metropoli/2015/07/8/mam-no-se-investiga-ebrard-por-la-l12 [fecha de consulta: 15 de julio de 2015].

${ }^{13}$ La noción affaire no se utiliza en este documento sino como sinónimo de "asunto" o "caso". El recurso a este galicismo no está sin embargo libre de intención; se pretende evocar el uso que comunmente se da a éste en la prensa cuando se hace referencia a asuntos no necesariamente judiciales pero judicializables a los que se les asigna el atributo de provocar "escándalo" (entendido éste como lo señala la segunda de sus acepciones en el diccionario de la Real Academia de la Lengua Española: Hecho o dicho considerados inmorales o condenables y que causan indignación y gran impacto públicos). Se trata pues de connotar que el "asunto" o "caso" tiene además ese atributo y que, apegandose a las convenciones que rigen el uso de ese término, puede ser equiparable a eso a lo que se hace referencia cuando se habla del "escándalo Watergate", del "Watergate scandal" o del "affaire/scandale du Watergate".

${ }^{14}$ Se trataba de la convocatoria a personas físicas y morales para participar en la licitación pública de carácter internacional, con recursos del Gobierno del Distrito Federal, para la contratación de obra publica en modalidad de proyecto integral a precio alzado y tiempo determinado, del proyecto para la construcción de la Línea 12 Tláhuac-Mixcoac del Sistema de Transporte Colectivo, que comprendía los estudios y análisis necesarios; anteproyectos; proyectos ejecutivos; construcción; instalaciones fijas; pruebas; marcha en vacío y puesta en servicio; capacitación y requerimientos del organismo operador. Esta convocatoria fue publicada en la Gaceta Oficial del Distrito Federal del 21 de enero de 2008.

${ }^{15}$ Acta de fallo y de adjudicación de Convocatoria Pública Internacional núm. 001 Licitación núm. 30001140001-08, del 8 de junio de 2008. En realidad el contrato sería suscrito el 17 de junio no sólo por parte de la empresa Ingenieros Civiles Asociados, sino por un consorcio integrado por ésta y por las empresas Carso Infraestructura y Construcción, SAB de CV y Alstom Mexicana, sA de Cv. Véase el contrato 8.07 C0 01 T.2.022.

${ }^{16} \mathrm{Se}$ trata del contrato de prestación de servicios para arrendar y dar mantenimiento a un lote de 30 trenes nuevos de rodadura férrea suscrito por el sTC Metro y las empresas, CAF México, SA de CV y Provetren, sA de cv, el 31 de mayo de 2010. Este contrato estipuló un monto de 1588152500.00 de dólares. 
cuando, con diez meses de retraso, fue inaugurada la línea 12 del Metro que meses más tarde, en marzo de 2014, sería parcialmente cerrada. La movilización de entidades públicas competentes para esclarecer las causas y responsabilidades del cierre parcial de tan costosa obra no esperó. A las encargadas de la procuración de justicia y las relacionadas con la responsabilidad de los servidores públicos, rápidamente se sumó la reacción de los órganos de representación popular, que conformaron comisiones de investigación para el caso. Gracias a una de éstas fue como se difundieron los detalles del caso en los medios de comunicación.

El informe presentado en febrero de 2015 por la comisión especial de la Cámara de Diputados del Congreso de la Unión conformada para dar seguimiento al ejercicio de los Recursos Federales destinados a la L12 del Metro, incluyó entre sus conclusiones que, al contratarse y administrarse diversos bienes y servicios relativos a la obra civil y electromecánica a través de diferentes unidades administrativas, a saber, la Dirección General de Obras de Transporte y Proyecto Metro del Distrito Federal y por otra parte el Sistema de Transporte Colectivo Metro (sTC), se generó cierta dispersión, y con ello, confusiones y problemas de coordinación. Dicho informe incluyó igualmente la observación de que el desgate ondulatorio, que constituyó la principal causa de la suspensión, había sido detectado dos meses antes de la inauguración de la línea, no obstante lo cual no se habían tomado las medidas necesarias para su corrección. El informe es enfático en que, a pesar de que se conocía ese problema antes de la inauguración de la línea, toda vez que el consorcio constructor había sustituido 900 metros de vía, los actores públicos involucrados, es decir el Proyecto Metro ${ }^{17}$ y el Sistema de Transporte Colectivo Metro, no hicieron nada para atenderlo. Según la comisión, debido a que se conocía este problema debió haberse contemplado de forma más precisa en el Manual de Mantenimiento y debieron tomarse acciones preventivas concretas por parte del Proyecto Metro, el consorcio y el STC.

Desde un primer informe se recomendaba a la Contraloría General del Distrito Federal revisar la existencia de acciones u omisiones que hubieran vulnerado la normatividad para eventualmente fincar las responsabilidades de los servidores públicos que hubieran tenido bajo su responsabilidad la obligación de haber incluido el desgaste ondulatorio en el Manual de Mantenimiento; y a aquellos responsables de la supervisión del proyecto en su construcción y opera-

\footnotetext{
${ }^{17}$ Proyecto Metro del Distrito Federal es un organismo desconcentrado de la Secretaría de Obras y Servicios, creado por una reforma al Reglamento Interior de la Administración Pública del Distrito Federal publicado en la $G a$ ceta Oficial del Distrito Federal del 24 de abril de 2009.
} 
ción. ${ }^{18}$ Así, en septiembre de 2014, esa Contraloría informaba que, concluidas las primeras auditorías e investigaciones, relativas a una primera etapa de la investigación que comprendió el periodo de 2008 a 2013 en lo concerniente a la planeación, licitación, racionalización, contratación de obra, modificación de trazo, convenios modificatorios al contrato principal, convenios de reconocimiento de adeudos, ejecución de obra, supervisión externa de la obra y entrega de la línea 12 del consorcio al Proyecto Metro del Distrito Federal, se había encontrado que 33 personas eran responsables de faltas y eran acreedoras a 54 sanciones (algunos servidores públicos habían sido objeto de más de una sanción). Informaba también que, a raíz de esas investigaciones, habían sido formuladas varias denuncias ante la Procuraduría General de Justicia del Distrito Federal por la probable responsabilidad penal de 15 funcionarios o ex funcionarios. Se trató de procedimientos de definición de responsabilidad de servidores públicos, en algunos casos varios procedimientos a una misma persona por los que se impusieron sanciones percibidas como desmesuradas y difícilmente aplicables pero con las que esa autoridad parecía estar respondiendo a una creciente imagen de indignación de algunos sectores de la población. ${ }^{19}$

También producto de esta serie de procesos de la aplicación de la reglamentación relativa al régimen de responsabilidad de los servidores públicos, esta entidad inhabilitó al titular de Proyecto Metro. La sanción impuesta al Ing. Enrique Horcasitas consistió en la inhabilitación para desempeñar cargos en la administración pública del Distrito Federal por un periodo de diez años así como en una multa que se eleva a 7.8 millones de pesos. ${ }^{20}$

Por otra parte, el segundo informe de la comisión especial conformada para dar seguimiento al ejercicio de los recursos federales destinados a la línea $12 \mathrm{del}$ Metro contenía, entre otras recomendaciones, una dirigida al procurador general de Justicia del Distrito Federal, solicitándole estudiar los posibles ilícitos cometidos y llevar a cabo el desglose correspondiente a la Procuraduría General de la República, para que, en el ámbito de sus atribuciones, esa otra procuraduría procediera a la averiguación de posibles delitos cometidos por funcionarios públicos y empresas privadas, relacionados con la L12 del Metro. ${ }^{21}$ Así, durante junio y

\footnotetext{
${ }^{18}$ Véase el primer informe preliminar de la comisión de investigación para conocer las razones que originaron la suspensión temporal del servicio en once estaciones de la línea 12 del Sistema de Transporte Colectivo Metro.

${ }^{19}$ Véase por ejemplo la nota del diario Excélsior del 22 de diciembre de 2014 "Fallas en la línea 12 afectan a miles; son incapaces de pagar. Las multas a los responsables son incobrables por elevadas, afirman especialistas".

${ }^{20}$ Imponen nueva sanción a Horcasitas. El Universal, 15 de julio de 2015.

${ }^{21}$ Boletín núm. 5205 "Conocen diputados segundo informe de la Comisión Especial sobre la línea 12 del Metro". Disponible en: http://www5.diputados.gob.mx/index.php/esl/Comunicacion [fecha de consulta: 15 de julio de 2015 ].
} 
julio de 2015, en atención a estas recomendaciones, la primera de esas procuradurías emitió comunicados por los que, como se mencionó antes, se dio a conocer el otorgamiento de órdenes de aprehensión contra altos funcionarios de la entidad Proyecto Metro, y la movilización de la Interpol por las averiguaciones previas integradas en contra del director de dicha entidad, así como de otros importantes funcionarios de la misma. Además de que sacudieron la opinión pública, estos anuncios pusieron en evidencia la concurrencia de comportamientos asociados a la construcción de la línea 12 del Metro de los que podrían desprenderse imputaciones sobre transgresiones a la regulación administrativa, penal, así como a la probidad pública.

Al correr la mitad del año 2015 eran varias las vías por las que las autoridades habían iniciado procedimientos para definir responsabilidades de los actores involucrados en la construcción de la L12 del Metro. ${ }^{22}$

Es también de conocimiento público, como fue mencionado al inicio de este artículo, que se han iniciado procedimientos de averiguación previa para definir la responsabilidad penal de varios funcionarios. En algunos casos, han sido libradas órdenes de aprehensión por jueces competentes y en otros, producto de la acumulación de elementos que hacen que se presuma la probable responsabilidad penal de esas personas, se han girado avisos a la policía internacional y ésta ha emitido las correspondientes fichas rojas para la detención de algunos de ellos, cuyo paradero es ignorado por la autoridad local de procuración de justicia, la Procuraduría General de Justicia del Distrito Federal. Éste es también el caso del ex titular del Proyecto Metro. ${ }^{23}$ Se habían iniciado igualmente procedimientos de averiguación previa por parte de la Procuraduría General de la República para determinar si en la construcción de la Línea 12 fueron transgredidas normas que regulan el uso de recursos provenientes del Presupuesto de Egresos de la Federación; y finalmente, tanto la Cámara de Diputados del Congreso de la Unión como la

${ }^{22}$ Boletín Informativo emitido por la Contraloría General del Distrito Federal, del 9 de septiembre de 2014.

${ }^{23}$ A principios de julio de 2015, la prensa informó que según la Procuraduría General de Justicia del Distrito Federal, la Interpol había emitido ficha roja para la búsqueda de Enrique Horcasitas junto con otros ex funcionarios de Proyecto Metro: Moisés Guerrero Ponce, que se había desempeñado como director de construcción de obras civiles, y Sergio Aguirre Mendoza, que había sido subdirector de obras y apoyo técnico. Entre otros véase el sitio electrónico de CNNexpansión, disponible en: http://noticias.univision.com/article/2393749/2015-07-07/mexico/noticias/interpolbusca-a-funcionario-mexicano-tras-fallas-en-la-construccion-de-linea-12-del-metro [fecha de consulta: 15 de julio de 2015]. Cerca de dos años más tarde, Horcasitas sigue sin haber sido detenido. Se sabe que de las 13 averiguaciones previas (carpetas de investigación) iniciadas, subsisten once, que involucran a 37 probables responsables sobre quienes hay órdenes de aprehensión. Véase El Financiero del 30 de marzo de 2017, disponible en: http://www.elfinanciero. com.mx/nacional/tribunal-amparan-a-dos-exfuncionarios-del-metro-por-linea-12.html [fecha de consulta: $30 \mathrm{de}$ julio de 2017]. 
Asamblea Legislativa del Distrito Federal han establecido comisiones especiales para investigar la presunta incidencia de conductas infractoras en la construcción de la L12 que llevaran a la suspensión de sus operaciones.

Llama la atención en esta movilización de instancias de procuración de justicia, su cantidad y diversidad, pero al mismo tiempo que parecían concentrarse en los actores públicos involucrados en la construcción de la L12. Esto tal vez se explica por el hecho de que el affaire se daba en un contexto en el cual el tema de la corrupción se había posicionado con firmeza en el debate público. En efecto, en el marco de la discusión sobre un sistema nacional anticorrupción, se había mencionado la necesidad de fortalecer el régimen de responsabilidades de los servidores públicos, en especial con el fin de revertir la elevada ineficiencia en la fiscalización, que sólo llega a establecer responsabilidades de servidores públicos en menos de 5 por ciento de las denuncias penales planteadas por corrupción. La Auditoría Superior de la Federación daba cuenta en sus informes que entre 1998 y 2012 se habían presentado 444 denuncias penales, y en muy pocos casos se había ejercido acción penal. ${ }^{24}$ Así, respecto a la cuenta pública de 2012, se presentaron 134 denuncias ante el Ministerio Público; de las 133 interpuestas en 2011, 129 estarían en trámite; 102 de las correspondientes a 2010; 34 de las presentadas en 2009 y diez correspondientes a 2008 (ASF, 2014: 139).

\section{Mucho ruido y pocas nueces}

La observación de Lascoumes y Nagels para el caso francés parecería en principio válida para México y nos orientaría a anticipar que las sanciones aplicadas en el caso de la Línea 12 del metro serán raras con respecto al número de personas y el tipo de actores involucrados. Sin embargo, es posible preguntar si en el caso de las faltas a la probidad pública y, en fin, de potenciales casos de corrupción estamos verdaderamente ante un caso en el que el conocimiento de esas transgresiones genera una gran cobertura mediática y una importante movilización de los aparatos de procuración de justicia, generando "mucho ruido" y entonces la expectativa de sanciones severas; o bien, si estaremos ante la situación socio-

\footnotetext{
${ }^{24}$ Como se señaló, el informe de la Auditoría Superior de la Federación para el ejercicio 2013 menciona que de esas 444 denuncias solo en siete casos hubo consignación al juez. A partir del informe relativo a 2014 sólo se informa del número de denuncias interpuestas por ese órgano pero no de las consignaciones ante tribunales penales. De 1998 a 2014 se habían acumulado 741 denuncias de hechos (ASF, 2017: 169). Según la declaración de Reyes Gamiz, fue en 4.2 por ciento de un número similar de denuncias en los que se generó una sanción. Véase "Castigan 3.2 por ciento de los casos de corrupción en México”, disponible en: http://www.excelsior.com.mx/nacional/2014/03/01/946347 [fecha de consulta: 5 de marzo de 2015].
} 
lógicamente relevante a la que se refieren Lascoumes y Nagel en la cual, a pesar de lo anterior, las consecuencias en términos de imposición de sanciones serán tímidas.

Sin agotar aquí el repertorio de interrogaciones que ha orientado los esfuerzos reconocidos al interior de este enfoque, puede mencionarse que una de las más importantes se refiere a la cuestión sobre si la atención debe focalizarse en primer término en el individuo, enfoque propio de la criminología tradicional o bien en los actores colectivos (Lascoumes y Nagels, 2014: 49). Otra cuestión, presente desde el trabajo seminal de Sutherland (1940) concierne a si las reacciones sociales suscitadas por este tipo de conductas transgresivas son diferentes de las generadas por la delincuencia ordinaria, así como respecto a si la severidad de las sanciones a una u otra clase de faltas son similares o diferentes (Lascoumes y Nagel, 2014: 55). Otra más se refiere al clivaje entre los enfoques que se concentran y que articulan sus razonamientos en torno a los actores y aquellos que se interesan en los actos transgresivos cometidos (Lascoumes y Nagels, 2014: 29). Estos amplios temas nos parecen sugerir una manera de leer lo que es hasta ahora conocido en el caso de la línea 12 del Metro o al menos formular algunas preguntas respecto a lo que es conocido en este asunto.

Es cierto que los mecanismos y los alcances de la difusión de casos de corrupción han cambiado en los últimos años en México. No sólo por la transformación de la relación entre los medios de comunicación y el gobierno (Guerrero, 2010), sino por la aparición de instituciones públicas para desarrollar e implementar principios, lineamientos y prácticas administrativas de combate a la corrupción (Lanz, 1987; Dussauge, 2010) que, al definir de forma más precisa tipos penales, infracciones administrativas, y crear y mantener mecanismos de definición de responsabilidad por parte de servidores públicos, originaron más espacios (u oportunidades) para que los funcionarios incurran en actos ilícitos. Los recientes casos, como el denominado asunto de la "casa blanca" de la esposa del presidente Enrique Peña ${ }^{25}$ o, recientemente, del uso para fines privados de un

\footnotetext{
${ }^{25} \mathrm{~A}$ finales de 2014 la periodista Carmen Aristegui dio a conocer el probable conflicto de intereses en la compra de la casa de la esposa del presidente, pues habría sido adquirida del Grupo Higa, empresa que había obtenido algunos contratos de construcción con diferentes gobiernos, y participaba en el consorcio ganador de la licitación del tren de alta velocidad México-Querétaro. Tras la publicación de eso, el presidente designó un secretario de la Función Pública (Virgilio Andrade) y lo instruyó para realizar una investigación que determinara si en efecto se había incurrido en conflicto de intereses entre la administración federal y el Grupo Higa. Numerosos medios dieron cuenta de esto. Puede consultarse en El Universal en línea: http://archivo.eluniversal.com.mx/primera-plana/2014/impreso/angelica-rivera-pone-en-venta-la-8216casa-blanca-8217-de-las-lomas-47618.html [fecha de consulta: 15 de julio de 2015].
} 
helicóptero de la Comisión Nacional del Agua por parte de su director, David Korenfeld, ${ }^{26}$ no hubieran provocado la misma reacción en los medios de comunicación ni en la sociedad hace tres décadas. Se puede entonces acordar que hay una mayor difusión de conductas presumiblemente ilícitas por parte de responsables políticos pero no puede establecerse con exactitud si ha disminuido la brecha entre lo que difunden los medios y la sanción finalmente definida por los órganos competentes. ${ }^{27}$

\section{Un actor disimulado: Las élites económicas}

Por otra parte, esa creciente visibilidad mediática de esta clase de affaires no significa mayor luz sobre todos los actores que podrían estar envueltos en esta clase de asuntos. Tampoco significa que esa difusión tenga una repercusión equivalente en las reputaciones de los implicados. Si se piensa en los recuentos de personalidades percibidas como corruptas en México, predomina una atención sobre el actor público: a guisa de ejemplo se puede reproducir la lista de la revista Forbes que incluye a los líderes sindicales del SNTE, del Sindicato de Pemex, al hermano de un ex presidente de la República, a cinco antiguos gobernadores de entidades federativas en México y a dos altos funcionarios de la pasada administración federal. ${ }^{28}$ Aunque no necesariamente son coincidentes en su totalidad, este rasgo de que aparezcan personas del sector público se repite en otras listas. ${ }^{29}$ Las notas periodísticas que difundieron y comentaron estos casos se concentraron en funcionarios públicos, pero se trata de comportamientos que difícilmente podrían incurrir en conductas ilícitas sin la cooperación de agentes privados. A ello podría agregarse que otro tipo de affaires son susceptibles de integrarse en esas enumeraciones y que bien podrían estar encabezadas por el denominado Fobaproa, el escándalo del

\footnotetext{
${ }^{26}$ La Secretaría de la Función Pública instauró un procedimiento de responsabilidad administrativa en contra de David Korenfeld, director de la Comisión Nacional del Agua por el uso indebido de un helicóptero oficial. El 30 de abril de 2015 esa misma dependencia encontró al funcionario administrativamente responsable y resolvió imponerle una sanción económica. El expediente 0006/2015, que alcanza 580 páginas, está disponible en el sitio electrónico de la Secretaría de la Función Pública: http://www.funcionpublica.gob.mx/index.php/temas/documentos-pot.html [fecha de consulta: 30 de julio de 2015].

${ }^{27}$ Otra fuente de este tipo de conductas, el INEGI, revela en un documento encaminado a mediar y analizar delitos contra las empresas que en 2011 la corrupción fue el tipo de delito que afectó con más frecuencia al sector privado, con 24.7 por ciento de los casos, seguido del robo o asalto (22.6\%) y la extorsión (14.5\%) (Mugellini, 2014).

${ }^{28}$ Esta lista puede consultarse en: http://www.forbes.com.mx/los-10-mexicanos-mas-corruptos-de-2013/ [fecha de consulta: 15 de marzo de 2015].

${ }^{29}$ Por no mencionar otras, puede consultarse la lista del sitio electrónico periodístico sin embargo.com disponible en: http://www.sinembargo.mx/24-07-2012/302100 [fecha de consulta: 10 de marzo de 2015].
} 
banco HSBC, ${ }^{30}$ y el del grupo Waltmart en México. ${ }^{31} \mathrm{Al}$ pensar en estos casos, aparece la pregunta sobre si el manejo de los medios está orientando la atención y la indignación del público hacia los servidores públicos y deja de lado los comportamientos y prácticas de agentes privados: la manera en que los grandes consorcios privados realizan actividades de seducción o instigación para obtener contratos de obra pública, evadir el pago de impuestos o para obtener autorizaciones (en o al margen del marco legal), todo ello parece generar una desaprobación menor que la que suscita el comportamiento de los servidores públicos involucrados. ${ }^{32}$ Así, aparece la interrogación sobre por qué a pesar de que algunas empresas podrían estar involucradas en el affaire de la L12, la cobertura en los medios y su impacto en la percepción del público es poco significativa en comparación con los servidores públicos. Si bien tres de las empresas responsables de la supervisión de las obras del Metro (Lumbreras y Túneles SA de Cv, Ingeniería, Asesoría y Consultoría SA de CV, y Empresa de Estudios Económicos y de Ingeniería SA de CV) fueron sancionadas por la Contraloría General del Distrito Federal, mediante el impedimento para participar en contratos en materia de obra pública por un plazo de dos años con órganos desconcentrados, delegaciones y entidades de la administración pública local, ${ }^{33}$ está claro el tratamiento desigual en la prensa y su efecto en el ánimo de los ciudadanos. Estas reacciones pero, sobre todo, ese tratamiento disímil hacia los agentes públicos y privados participantes en el caso de la línea 12, interpelan al observador en el mismo sentido que otras situaciones han interpelado y suscitado interrogaciones sobre las élites delincuentes.

\footnotetext{
${ }^{30}$ En el caso de este banco, en julio de 2012, un subcomité del Senado de los Estados Unidos encontró que HSBC México mostraba entre sus prácticas algunas proclives al lavado de dinero, como la ausencia de políticas para conocer al cliente, un sistema de monitoreo disfuncional y usuarios de alto perfil involucrados en el tráfico de drogas. Para este subcomité, HSBC México sería el principal exportador de dólares a la filial estadounidense de ese banco, transfiriendo 3000 millones de dólares en 2007 y 4000 millones de dólares en 2008, cifras que sólo podrían haber alcanzado ese volumen si incluían dinero producto de actividades ilícitas. Véase Expansión, disponible en: http://www.cnnexpansion.com/negocios/2015/02/09/hsbc-tiene-un-historial-de-escandalos-en-el-mundo [fecha de consulta: 30 de marzo de 2015].

${ }^{31}$ En abril de 2012, el influyente diario The New York Times reveló que la subsidiaria en México de esa empresa había pagado un poco más de 24 millones de dólares a autoridades locales (alcaldes, regidores, burócratas de bajo nivel encargados de emitir permisos, supuestos planificadores...) en México para obtener modificaciones en el uso de suelo y agilizar permisos de construcción. Disponible en: http://www.nytimes.com/2012/04/22/business/at-wal-mart-inmexico-a-bribe-inquiry-silenced.html?_r=2\&hp [fecha de consulta: 10 de marzo de 2015].

${ }^{32}$ Son escasos los ejercicios que recogen una valoración respecto a los agentes del sector privado. Pueden destacarse las encuetas realizadas por KPMG (2008) y el CESOP (2016), así como el documento México: Anatomía de la corrupción (Casar, 2016).

${ }^{33}$ Véase el aviso de la Contraloría General del Distrito Federal CGDF/I/002/2015 publicado en Gaceta Oficial del $D F$ el 12 de febrero de 2015. Igualmente puede consultarse la página internet de la Agencia de Gestión Urbana de la Ciudad de México: http://www.agu.df.gob.mx/sintesis/index.php/contraloria-df-inhabilita-3-empresas-que-inspeccionaron-la-112/ [fecha de consulta: 15 de julio de 2015].
} 


\section{Percepciones y representaciones}

En efecto, uno de los aspectos en los que más se interesa la sociología de las élites delincuentes son las asimetrías en las percepciones del público sobre los comportamientos ilícitos de ese tipo de población; es decir, lo que es sociológicamente misterioso para este enfoque es por qué, a pesar de la dimensión y difusión de asuntos y escándalos de corrupción que involucran a élites políticas y a élites económicas, las respuestas sociales y penales son en su mayoría débiles y en general, escasas, o bien, por qué situaciones o escándalos similares puede generar percepciones disímiles en el público. Cierto, la percepción sobre los hechos no necesariamente significa que aparecerá una reacción social o punitiva, o que ésta corresponderá a la gravedad con la que se percibe la falta. Sin embargo, la forma en que los comportamientos se perciben constituye un presupuesto para que se desencadene alguna de esas respuestas. Si bien son numerosas las limitaciones que impone la escasez de fuentes de información sobre los procesos para determinar responsabilidades, o las que se derivan del principio de reserva de las actuaciones procesales relacionadas con el caso de la L12, con el propósito de contar con algunos elementos para analizar cómo los enigmas de la sociología de las élites delincuentes se actualizan en nuestro caso, hemos revisado algunos de los registros disponibles sobre cómo son percibidas diferentes personas y entes públicos y privados respecto a su papel en el escándalo de la llamada Línea Dorada.

Meses después del cierre de la L12 del Metro, un estudio de opinión del Gabinete de Comunicación Estratégica realizado en marzo de 2014 atribuía poco más de 37 por ciento de la culpa sobre el cierre de la L12 a actores privados (22.5\% culpaba a los certificadores internacionales que avalaron el proyecto; $11.8 \%$ a los constructores de las vías y $3.3 \%$ a los fabricantes de los trenes), 19.2 por ciento culpaba a los funcionarios que autorizaron la obra y sólo 13.3 por ciento al ex jefe de gobierno. ${ }^{34}$

Las opiniones sin embargo varían según la encuesta y el momento de su realización. Otro estudio de opinión, elaborado en abril de 2014, reveló que 58 por ciento de los habitantes de la zona metropolitana del Distrito Federal le atribuían al ex jefe de gobierno la responsabilidad de los problemas de esta línea del metro, que 20 por ciento se lo atribuía a las empresas constructoras y 12 por ciento al

\footnotetext{
${ }^{34}$ Estudio de Opinión Línea Dorada sin brillo, elaborado el 18 de marzo de 2014. Disponible en el sitio electrónico del Gabinete de Comunicación Estratégica: http://www.gabinete.mx/index.php?option=com_k2\&view= item\&id=55:lineadorada-sin-brillo [fecha de consulta: 15 de julio de 2015].
} 
actual jefe de gobierno. Justamente respecto a la imputación espontánea de la ciudadanía hacia las empresas participantes en la construcción de la L12, la encuesta revela que 41 por ciento consideraba responsable a las autoridades del gobierno de la ciudad, mientras que 35 por ciento cree responsables a las empresas participantes por hacer mal la obra o engañar al gobierno. Esta encuesta señala también que 77 por ciento de los encuestados se muestran escépticos respecto de que se vaya a castigar a los responsables. ${ }^{35}$ También sobre el impacto del caso de la L12 en la imagen pública, tanto del ex jefe como del actual jefe de gobierno del Distrito Federal, otro sondeo de junio de 2014 reveló que la imagen pública empeoró para ambos, 39 por ciento en el caso del actual jefe de gobierno y 60 por ciento en el caso del ex jefe de gobierno, a quien 40 por ciento de los encuestados señalaron como el responsable del cierre de la L12 del Metro. ${ }^{36}$

En otro estudio, elaborado ya en 2015, un mayor número de encuestados, 60.6 por ciento, consideraron responsables a las empresas constructoras en tanto que solo 36.5 por ciento las eximía. El juicio de los encuestados era similar con los funcionarios públicos: según 58.8 por ciento, el cierre parcial de la L12 era culpa del ex titular de Proyecto Metro, el ingeniero Enrique Horcasitas y 56.9 por ciento consideraba culpable al el ex jefe de gobierno Marcelo Ebrard, mientras que 40.2 por ciento lo consideraba inocente. ${ }^{37}$

También en ese ańo, en marzo, otro estudio de opinión reveló que 75 por ciento de los entrevistados decían estar enterados de que el ex jefe de gobierno estaba siendo investigado por el asunto de la L12 y de ellos, 90 por ciento consideraban que se trataba de una noticia grave o muy grave. Asimismo, esa consulta dejaba ver que 66 por ciento de los encuestados declaraban culpable al ex jefe de gobierno del cierre de la Línea Dorada y, por otro lado, cuantificaba una mala o muy mala opinión sobre él, antes y después del conocimiento del affaire: esta opinión desfavorable había pasado de 28 a 62 por ciento. ${ }^{38}$ En general, el paso del tiempo

${ }^{35}$ Se trata de la nota de Ulises Beltrán y Alejandro Cruz/ BGC, Beltrán, Juárez y Asociados publicada en Excélsior, disponible en: http://www.excelsior.com.mx/nacional/2014/04/14/953989\#imagen- 4 [fecha de consulta: 15 de julio de 2015]. El resultado de la encuesta puede también consultarse en el sitio electrónico de Beltrán, Juárez y Asociados, disponible en: http://www.bgc.com.mx/encuesta-bgc-excelsior/180-culpan-a-ebrard-por-linea-12 [fecha de consulta: 15 de julio de 2015].

${ }^{36}$ Véase el sitio electrónico de Consultoría Política y Estudios de Opinión Varela y Asociados, disponible en: http://www.varelayasociados.com.mx/encuesta-en-el-distrito-federal-junio-2014/\# [fecha de consulta: 15 de julio de 2015].

${ }^{37}$ Este estudio, elaborado por Gabinete de Comunicación Estratégica (GCE) está fechado en febrero de 2015. Puede consultarse en: http://www.kaleydoscopio.mx/index.php/archiveros/item/2772-linea-12-del-metro-del-dorado-a-mas-negro-que-la-noche [fecha de consulta: 15 de julio de 2015].

${ }^{38}$ Encuesta levantada el 15 de marzo de 2015 a mil personas mayores de 18 años por vía telefónica por sDP Noti- 
no parece haber modificado la percepción sobre la responsabilidad del ex jefe de gobierno mientras que esa tendencia negativa en la reputación no presentó un comportamiento similar respecto a las empresas involucradas.

El impacto del cierre de la L12 en la percepción que tiene la ciudadanía de los involucrados, al no ser similar en todos los casos, genera algunas interrogaciones. En la síntesis que nos presentan Lascoumes y Nagels (2014) sobre los estudios de la sociología de las élites delincuentes se sugiere que la personalización de responsabilidades, la focalización sobre algunos personajes, sobre ciertos dirigentes, suele esconder la ayuda y complicidad, activa o pasiva, de algunos otros actores. El desarrollo de las investigaciones sobre la definición de responsabilidades en el caso de la L12 del Metro no permite en este momento trasladar plenamente esta observación a nuestro caso, pero es posible que en el futuro aparezcan elementos para acordar que efectivamente la focalización del affaire en algunos personajes ocultó la participación de otros y desplazó la posibilidad de definir su responsabilidad. Por lo pronto, debe subrayarse que además de este efecto desigual en la reputación de los involucrados, considerando los funcionarios con respecto a quienes no lo son, se aprecia una similitud considerable respecto al tipo de responsabilidad que se define en cada procedimiento jurisdiccional: si es administrativa, como en el caso de la responsabilidad de los servidores públicos o bien si es de índole penal. Así, el procedimiento de investigación orientado a determinar la responsabilidad penal de algunos funcionarios por la comisión del delito de uso ilegal de atribuciones y facultades (regulado por el artículo 267 del Código Penal del Distrito Federal), ${ }^{39}$ en que presuntamente incurrieron al haber autorizado contratos para la realización de una obra de la que se había declarado desierto el proceso de licitación, no genera el mismo tipo de atención y descredito que una sanción estrictamente administrativa, como una multa o inhabilitación para ejercer el servicio público. Más aún, puede plantearse la pregunta sobre si el hecho de que una conducta esté definida como delito en un código penal o en alguna otra ley se traduce en los hechos en prácticas de administración de justicia desiguales. La pregunta que aparece inmediatamente es respecto a la aceptabilidad por parte de la población y la pasividad de las instancias de procuración de justicia ante ciertas prácticas en que reiteradamente incurren algunos funcionarios públicos, especialmente en periodos electorales, que se asemejan a

cias, disponible en: http://www.sdpnoticias.com/nacional/2015/03/18/marcelo-ebrard-dana-a-movimiento-ciudadano-encuesta [fecha de consulta: 15 de julio de 2015].

${ }^{39}$ Publicado en la Gaceta Oficial del Distrito Federal del 16 de julio de 2002. Su última modificación se publicó el 18 de diciembre de 2014. 
lo que definen los códigos penal federal y del Distrito Federal como tráfico de influencias (artículos 221 y 272 respectivamente)..$^{40}$ Este tipo de conductas no suele generar la reprobación ni el eco mediático que corresponde a su escala generalizada en esos periodos. Además de estos delitos poco sancionados jurídica y socialmente, los delitos que la doctrina considera como delitos de cuello blanco suelen, por otra parte, estar definidos en legislaciones diferentes al Código Penal (Lozano, 2011), como es el Código Fiscal de la Federación o la Ley de Instituciones de Crédito. Esto a pesar de que, como ocurre en otros sistemas jurídicos, la doctrina los considera dentro de una subcategoría del derecho penal: el derecho penal especial denominado derecho penal de negocios. A este respecto, se actualiza la pregunta sobre si el hecho de que ciertas conductas no estén incluidas en leyes penales, significa que sean consideradas como socialmente menos peligrosas que los delitos ordinarios o al menos que sean vistas como conductas más aceptables en el seno de una sociedad.

\section{Algunas lecciones de la línea 12}

Aunque en su mayoría preliminares, el caso de la L12 del Metro ofrece ya algunas lecciones respecto a la naturaleza de las reglas transgredidas por los actores involucrados, la real incidencia de las conductas transgresoras, la naturaleza jurídica de los bienes jurídicos tutelados por las normas (en el caso de que se trate de normas de derecho) y respecto al perfil socioeconómico de los actores o la ocupación de éstos. Si nos limitamos a subrayar aquello que es puesto en evidencia al movilizar el enfoque de la sociología de las élites delincuentes, esas lecciones parecen todavía menos concluyentes, pero sugieren claramente algunas consideraciones. En primer término, respecto a la reacción social ante comportamientos como los relacionados con este caso: la mayor o menor susceptibilidad de que esas conductas sean estigmatizadas (respecto a lo que ocurre con las conductas relativas a delitos convencionales), la tolerancia que pueden suscitar respecto a las transgresiones de otros actores y, en general, la capacidad de las élites para escapar o a estar al abrigo de los apremios institucionales a los que están sometidos los miembros de otras clases sociales.

En el caso de la L12 del Metro, la sucesión de acciones asociadas a procedimientos por los que se define responsabilidad administrativa o incluso de servi-

${ }^{40}$ Ambos artículos definen el delito de tráfico de influencias. En el caso del Código Penal del Distrito Federal, el artículo 272 define que se configura este delito cuando un servidor público, "por sí o por interpósita persona, promueva o gestione la tramitación de negocios o resoluciones públicas ajenos a las responsabilidades inherentes a su empleo, cargo o comisión. Publicado en la Gaceta Oficial del Distrito Federal el 16 de julio de 2002. 
dores públicos, si bien puede constituir el inicio de una serie más amplia de procesos de imputación y condenación de responsables en este affaire, también puede ser parte de una reacción punitiva, ciertamente severa y expedita, pero selectiva, pues sólo se aboca a los servidores públicos y deja sin sancionar con la misma severidad a actores del sector privado que pudieran haber estado involucrados en la comisión de conductas delictivas.

La multiplicación de normas jurídicas, de instancias de procuración de justicia penal y de establecimiento de responsabilidad administrativa para perseguir y sancionar los comportamientos transgresores de la ley (Dussauge, 2010), parecerían no haberse erigido como elementos disuasorios para quienes incurren en esos comportamientos. Esto tendría otro efecto: puesto que esos comportamientos tampoco son percibidos como amenazas reales a los valores fundamentales de la sociedad, no generarían en consecuencia reprobación por parte de ésta. Esta desdramatización de los escándalos podría encontrar explicación en varios elementos pero, en todo caso, como se aprecia en el asunto de la Línea Dorada, la tecnicidad de los expedientes, la dificultad para identificar a los autores y, entre otros factores, la dilación de los procedimientos, podrían también estar en el origen de una explicación sobre por qué, a pesar de la gravedad de los casos (o la percepción de ésta), con el tiempo esa gravedad se desdibujara dando lugar, primero, a una dramatización del asunto, y luego, a una invisibilidad y finalmente una suerte de amnesia social sobre el caso.

¿Qué más generaría esa dinámica en la respuesta social a los delitos de las élites? Por un lado, a pesar de la movilización o agitación de los medios de comunicación, los actos de corrupción serían susceptibles de seguir siendo, o bien poco percibidos, o bien percibidos como algo desprovisto de gravedad por la mayoría de la sociedad. Y es que, al tratarse de un ilícito "sin víctima" o en donde la víctima es indirecta o difusa, sigue siendo difícil responder a la cuestión sobre a quién beneficia revelar o hacer retroceder la corrupción.

$\mathrm{Al}$ abrigo de la estigmatización social, toda una serie de conductas transgresoras de los normas legales y éticas de los responsables políticos habrían estado construyendo en México un espacio social en el que la corrupción se habría consolidado como un "crimen blanco" (Lascoumes, 2000), en tanto aceptada por las élites y tolerada por las poblaciones. Esta débil reacción social puede explicarse sin duda por un servicio de sustitución que si bien es insatisfactorio, minimiza el enfado contra la falta de funcionamiento del Metro, aunque con un costo considerable para el gobierno, es decir para el contribuyente del Distrito Federal: de acuerdo con la cadena televisiva CNN (información que a su vez obtuvo como 
respuesta a una solicitud de información por vía del sistema de transparencia), entre el momento del cierre de las once estaciones de la L12 y el 30 de abril de 2015, el gobierno gastó más de 318 millones de pesos (770 206 diarios y que significa 18.3 por ciento del presupuesto de la Red de Transporte de Pasajeros del Distrito Federal de 2015) en brindar el servicio de transporte en forma gratuita en el tramo que corresponde a las once estaciones cerradas de la L12. ${ }^{41}$ Estamos sin embargo, en nuestro caso de la L12 del Metro, ante una situación en la cual, aunque masivas ( $400 \mathrm{mil}$ personas que utilizaban esa línea), las víctimas son singulares, es decir son una población más o menos identificable o, en todo caso, una víctima menos abstracta que cuando se trata del "contribuyente", y en donde la afectación, por decir lo menos, es directa. Si bien la perspectiva de fuertes sanciones no parece clara en el horizonte al día de hoy, la visibilidad social y la desaprobación habría estado expresándose en los últimos meses.

Las preocupaciones que han dado lugar a trabajos sobre las élites delincuentes bien podrían ayudarnos a estructurar una forma más de ver lo que ocurre en torno al caso de la L12 del Metro, independientemente de que los procedimientos de definición de responsabilidades están aun lejos de llegar a su fin. G气

\section{REFERENCIAS BIBLIOGRÁFICAS}

ASF (Auditoría Superior de la Federación) (2014), Informe General: Cuenta Pública 2013, Ciudad de México, ASF /Cámara de Diputados, disponible en: http://www.asf.gob.mx/

Section/58_Informes_de_auditoria [fecha de consulta: 30 de junio de 2017]. ASF (Auditoría Superior de la Federación) (2017), Informe General: Cuenta Pública 2015,

Ciudad de México, ASF/Cámara de Diputados, disponible en: http://www.asf.gob.mx/ Section/58_Informes_de_auditoria [fecha de consulta: 30 de junio de 2017].

Bezes, Philippe y Pierre Lascoumes (2005), "Percevoir et juger la 'corruption politique':

Enjeux et usages des enquêtes sur les représentations des atteintes à la probité publique", Revue Française de Science Politique, 55(5-6), pp. 757-786.

Casar, María Amparo (2016), México: Anatomía de la corrupción (2a. ed.), México, Mexicanos Contra la Corrupción y la Impunidad (MCCI), disponible en: https://contralacorrupcion.mx/anatomia-segundaedicion [fecha de consulta: 7 de junio de 2018]. CESOP (Centro de Estudios Sociales y de Opinión Pública) (2016), Transparencia y rendición

\footnotetext{
${ }^{41}$ Véase la nota de Mauricio Torres "Los autobuses que suplen a la línea 12 cuestan 770000 pesos al día" del $1^{\circ}$ de julio de 2015, disponible en: http://mexico.cnn.com/nacional/2015/07/01/los-autobuses-que-suplen-a-la-linea-12cuestan-770000-pesos-al-dia [fecha de consulta: 14 de julio de 2015].
} 
de cuentas. Encuesta telefónica nacional, noviembre 2016, México, Cámara de diputados LXII Legislatura-Centro de Estudios Sociales y de Opinión Pública.

Crozier, Michael J., Samuel P. Huntington y Joji Watanuki (eds.) (1975), The Crisis of Democracy: Report on the Governability of Democracies to the Trilateral Commission, Nueva York: New York University Press.

Del Pont K., Luis Marco y Abraham Nadelsticher (1981), Delitos de cuello blanco y reacción social, Ciudad de México: Cuadernos del Instituto de Ciencias Penales.

Del Pont K., Luis Marco y Abraham Nadelsticher (1982), Delitos de cuello blanco y reacción social, Ciudad de México: Cuadernos del Instituto de Ciencias Penales.

Dussauge, Mauricio (2010), "Combate a la corrupción y rendición de cuentas: Avances, limitaciones, pendientes y retrocesos”, en José Luis Méndez, Los grandes problemas de México XIII, Políticas Públicas, Ciudad de México: El Colegio de México, pp. 207-252. Fernández, Gabriel y Efrén Arellano (2012), ¿Por qué legislar el combate al lavado de dinero?, Ciudad de México: Centro de Estudios Sociales y de Opinión Pública.

Geis, Gilbert (coord.) (2007), White-Collar Criminal: The Offender in Business and the Professions, New Brunswick: Transaction Publishers.

Guerrero, Manuel (2010), "Los medios de comunicación y el régimen político", en Soledad Loaeza y Jean François Prud'homme, Los grandes problemas nacionales de México XIV: Instituciones y procesos politicos, Ciudad de México: El Colegio de México, pp. 231-300. Hassenteufel, Patrick (2008), Sociologie politique: l'action publique, París: Armand Collin. INEGI (Instituto Nacional de Estadística y Geografía) (2014), Encuesta Nacional de Calidad e Impacto Gubernamental 2013 (ENCIG), tabulados básicos 2014, Ciudad de México: INEGI, disponible en: http://www3.inegi.org.mx/sistemas/tabuladosbasicos/tabdirecto. aspx?s=est \&c=33663 [fecha de consulta: 15 de julio de 2015].

Kingdon, John W. (1984), Agendas, Alternatives and Public Policies, Boston: Little Brown. KPMG (2008), Encuesta de fraude y corrupción en México 2008, México, KPMG, disponible en: www.funcionpublica.gob.mx/web/doctos/transparencia/focalizada/indices/05. pdf [fecha de consulta: 7 de junio de 2018].

Lanz, J. Trinidad (1987), La Contraloría y el control interno en México: Antecedentes históricosy legislativos, Ciudad de México: SCGF/FCE.

Lascoumes, Pierre (2000), Corrupciones: El poder frente a la ética, Barcelona: Bellaterra.

Lascoumes, Pierre (2011), Une démocratie corruptible, París, Seuil.

Lascoumes, Pierre y Carla Nagels (2014), Sociologie des élites délinquantes, París: Armand Collin.

Lascoumes, Pierre y Patrick LeGalès (2014), Sociología de la acción pública, Ciudad de México: El Colegio de México.

Lozano, Antonio (2011), “Aspectos político-criminales de los delitos de cuello blanco", en 
José R. Roque (coord.) (2011), Delitos de cuello blanco, Ciudad de México: Instituto Nacional de Ciencias Penales, pp. 20-44.

Mugellini, Giulia (2014), Medición y análisis de la delincuencia contra el sector privado: Experiencias internacionales y el caso mexicano, Ciudad de México: INEGI.

Newman, Donald, J. (1958), "White-Collar Crime", Law and Contemporary Problems, 23, pp. 735-753, disponible en: http://scholarship.law.duke.edu/lcp/vol23/iss4/9 [fecha de consulta: 6 de abril de 2015].

Parsons, Wayne (2005), Políticas públicas, Ciudad de México: Flacso México/Miño y Dávila. Pharr, Susan J. y Robert D. Putnam (eds.) (2000), Disaffected Democracies: What's Troubling the Trilateral Countries?, Princeton: Princeton University Press.

Plascencia, Raúl (1995), Los delitos contra el orden económico: La responsabilidad penal de la persona jurídica, Ciudad de México: UnAm.

Rebovich, Donald J. y Jenny Laine (2000), The National Public Survey on White Collar Crime, Morgantown: National White Collar Crime Center.

Roque, José R. (coord.) (2011), Delitos de cuello blanco, Ciudad de México: Instituto Nacional de Ciencias Penales.

Simonetti, José, M. y Julio E.S. Virgolini (1990), Del delito de cuello blanco a la economía criminal, Ciudad de México: Instituto Nacional de Ciencias Penales.

Sutherland, Edwin H. (1940), "White-collar Criminality", American Sociological Review, 5(1), pp. 1-12.

Sutherland, Edwin H. (1949), White Collar Crime, Nueva York: The Dryden Press.

Sutherland, Edwin H. (1969), El delito de cuello blanco, Caracas: Universidad Central de Venezuela.

Tremblay, Pierre, Martin Bouchard y Chloé Leclerc (2006), "La courbe de gravité des crimes", L'Anée sociologique, 56(1), pp. 201-227.

Vilalta, Carlos y Gustavo Fondevila (2013), Perfiles criminales I: Frecuencias y descriptivos, Ciudad de México: CIDE.

Wolfgang, M.E., R.M. Figlio, P.E. Tracy y S.I. Singer (1991), The National Survey of Crime Severity, Washington, D.C.: U.S. Government Printing Office. 
Vicente Ugalde es profesor-investigador de El Colegio de México. Doctor en Derecho (Universidad Panthéon-Assas, París 2). Su trabajo se centra en la gobernanza en metrópolis; las políticas ambientales, su implementación; la toma de decisiones legales en política urbana y ambiental; la juridización del ambiente y en los conflictos socioambientales. Imparte, entre otros, el curso de "Gestión Local". Fue profesor-invitado en la Universidad de Montreal, en el Centro de Estudios Europeos de Science-Po (París) y en el Citeres (Universidad de Tours). Fue miembro de consejo editorial de la Revista de Administración Pública; es miembro del comité editorial de la revista Espacialidades y del comité editorial del CIESAs. Es nivel II del Sistema Nacional de Investigadores. 